\title{
Prevalence and Risk Factors of Depression and Anxiety in Hepatitis C Patients Receiving Pegylated Interferon Alpha (IFN-a)
}

\author{
Sahar M. Hassany*, Alaa M. Darwish, Hossam Khalifa, Gellan K. Ahmed, \\ Haidi Karam Alla Ramadan and Ehab F. Moustafa \\ Tropical Medicine and Gastroenterlogy, Assiut University Hospitals, \\ Alrajhy Liver Hospital, Assiut, Egypt \\ *Corresponding author
}

\section{A B S T R A C T}

It is well known that interferon alpha (IFN-a) therapy given to patients with $\mathrm{HCV}$ and canceris associated with the development of depression and anxiety. However, the strength of association is often questioned among different studies. Aim of the study is to determine the prevalence of depression and anxiety in chronic hepatitis $\mathrm{C}$ patients receiving pegylated interferon alpha (PegIFN) and ribavirin (RBV) therapy and to detect the possible risk factors for development of these adverse events. A total of 100 chronic HCV patients eligible for interferon therapy from the hepatitis outpatient clinic of Assiut University

\section{Keywords}

Preelance, Risk factor, Hepatitis C, Patients.

\section{Article Info}

Accepted:

07 September 2017 Available Online: 10 October 2017 Hospital were included. Full medical assessment was done before initiation of the treatment. Assessment of the psychiatric history and examination by using (DSM-IV), structured interview for the five factor model of personality and psychiatric questionnaires using Hamilton depression (HD) and Hamilton anxiety (HA) scores to assess the severity of depression and anxiety were done. Both medical and psychiatric assessment was done at the start of the study and after starting the treatment at 2 months, 4 months and 6 months. At initiation of the study all patients had normal HA and HD scores. Depression developed in $69 \%, 60.2 \%$ and $60.2 \%$ after 2 months, 4 months and 6 months of IFN therapy, respectively. While about $9 \%, 8.6 \%$ and $6.9 \%$ developed anxiety after 2,4 and 6 months of treatment, respectively. Most of the patients developed mild to moderate depression. No case developed moderate or severe anxiety. Most of these cases developed manifestations after 2 months of starting the treatment, 69\% developed depression and $9 \%$ developed anxiety. There was a correlation between depression and anxiety during IFN treatment ( $p=$ 0.000 ). Other risk factors to develop these side effects included smoking, neuroticism and patients concerns as regard development of other side effects that decrease quality of life, treatment duration and failure of response and rumors of new drugs such as DAAs. IFN induced depression and anxiety in chronic HCV patients are common. These are considered side effects of the drug and not direct effect of the virus. Patient's personality and other patients concerns regarding treatment are considered the main risk factors in our

\section{Introduction}

Chronic hepatitis $\mathrm{C}$ virus (HCV) infection affects about 185 million all over the world (1). Egypt has the highest prevalence of chronic $\mathrm{HCV}$ in the world ranging from $6 \%$ to $40 \%$ with an average rate of $14.7 \%$ (2). Standard of care treatment for all virus 
genotypes was combination of pegylated interferon alpha (PegIFN) and ribavirin (RBV). This combined treatment has been associated with awide range of adverse events including neuropsychiatric side effects. Although new directly acting antiviral drugs (DAAs) replaced standard of care treatment, IFN was used in combination with these drugs at the beginning.

Interferon (IFN) is a pro-inflammatory cytokine, it affects the function of immune system resulting in marked anti-viral, anticancer, and has an immunomodulatory effects. FDA approved its use for several diseases such as multiple sclerosis, malignant melanoma, chronic myeloid leukemia, and $\mathrm{HCV}$ infection (3).

It is well known that interferon alpha (IFN-a) therapy given to patients with $\mathrm{HCV}$ and cancer is associated with the development of depression. However, the strength of association is often questioned because many of the studies have not used objective and validated measures of depressive symptomsor criterion-based instruments (4).

Although pegylated IFN-a has improved the efficacy of response, depression still occurs in patients with $\mathrm{HCV}$ who receive peglylated IFN-a (5). Depression induced by IFNis common and can result in discontinuation of IFN therapy and the use of pharmacologic drugs to treat it (6). About one third of HCV patients develop depression (7) and 10-20\% develop anxiety after IFN treatment (8).

There are discrepancies in the prevalence of depressive symptoms and anxiety in different studies. Differences in type, dose, duration of IFN therapy and differences within the studied patient populations are causes of variation. Furthermore, the symptoms, time course, risk factors, etiology, and treatment of IFN-induced depression are poorly understood and not well characterized in research studies.

The aim of this study was to determine the prevalence of depression and anxiety in chronic hepatitis $\mathrm{C}$ patients receiving pegylated interferon alpha (PegIFN) and ribavirin (RBV) therapy and to detect the possible risk factors for development of these adverse events.

\section{Patients and Methods}

This prospective observational study was conducted on 100 chronic HCV patients with compensated liver disease attended the hepatitis outpatient clinic of Assiut University Hospital during the period from September 2013 to January 2015.They were eligible to receive IFN-based combination therapy with weight-based ribavirin according to the guidelines of the National Committee for Control and Prevention of Viral Hepatitis C in Egypt. The dose of peg-IFN alpha 2-a or alpha 2-b was $180 \mathrm{mg}$ for IFN alpha 2-a and $1.5 \mathrm{mg}$ for IFN alpha 2-b subcutaneously once weekly according to body weight and ribavirin (1000-1200 mg/day oral depending on body weight).

Patients were excluded if they had history of previous mental illness or were taking drugs that affect the relationship between mood and IFN- $\alpha$ such as anticonvulsants or alcohol.

This study was approved by the local ethical board in Faculty of Medicine, Assiut University, Egypt. All the included patients gave an informed written consent prior to their participation.

The included patients at the start of the study had full medical assessment including history, examination, ultrasound and laboratory tests including quantitative PCR for $\mathrm{HCV}$, complete blood picture, liver function test and 
prothrombin time. Liver biopsy were done to assess the grade and stage of hepatitis before initiation of treatment. During the study, patients were followed up weekly by clinical medical assessment and laboratory assessment by another liver function test, prothrombin time and complete blood picture. At 3 months and 6 months follow up, HCV qualitative PCR was done to monitor the viral response.

Assessment of the psychiatric history and examination by using the Diagnostic and Statistical Manual of Mental Disorders (DSM-IV) (9). Furthermore, the structured interview for the five factor model of personality, socioeconomic status scale for family and psychiatric questionnaires using Hamilton depression (HD) and Hamilton anxitey (HA) scores to assess the severity of depression and anxiety were also done.

This psychiatric assessment was done at the start of the study and then during follow up during the treatment at 2 months, 4 and 6 months.

\section{The structured interview for the five factor model of personality (Arabic version)}

Translated by El Telawy H., Hadhoud E. and El Nasser W; in which the following domains and facets of personality are assessed Neuroticism, Extraversion, Openneness to experience, Agreeableness and conscientiousness (10).

\section{Socioeconomic status scale for family}

This scaleis to assess socioeconomic status of the family and consists of 4 dimensions, which include the following: Parent's level of education, Parent's occupation, Total family monthly income and Life style of the family (11). The total score of the scale equal the sum of scores in each level, the scores 36-42 mean the high socioeconomic class, the scores
21-26 mean the low socioeconomic class, and scores between them mean the middle class.

\section{Psychiatric questionnaires}

\section{Hamilton depression scale assessment}

It is clinical rating scale for assessment of severity of depression. The total score is obtained by summing the score of each item, 0-4 (symptom is absent, mild, moderate, or severe). For the 17-item version, scores can range from 0 to 54 .

Where total scores between 0 and 7 do not indicate the presence of depression, scores between 8 and 13 indicate mild depression, scores between 14 and 18 indicate moderate depression, scores between 19 and 22 indicate severe depression and 23 score or more indicate very severe depression.

\section{The Hamilton anxiety rating scale}

Is clinician-rated scale that is intended to provide an analysis of the severity of anxiety. The scale consists of 14 items, each defined by a series of symptoms, and measures both psychic anxiety (mental agitation and psychological distress) and somatic anxiety (physical complaints related to anxiety).Each item is scored on a scale of 0 (not present) to 4 (severe), with a total score range of $0-56$, where total score $0-13=$ normal, $14-17=$ mild anxiety, $18-24=$ moderate anxiety, $25-30=$ severe anxiety.

\section{Statistical analysis}

Data processing and statistical analysis was performed using the software packages SPSS (version 16). The Mann_Whithney U-test and Kruskal_Wallis test were used to investigate associations between demographic and psychopathological variables. Correlations between psychopathological scores (depression, anxiety, social functioning) and 
neuropsychological test parameters as well as virological features were analysed by Spearman correlations. All tests were twotailed and P- values less than 0.05 was considered significant.

\section{Results and Discussion}

\section{Sociodemographic data of the patients}

Out of 100 included chronic $\mathrm{HCV}$ patients there were 87 males and 13 females. Their mean age was39.07 \pm 10.70 and range between 18 and 59 years. The duration of hepatitis was less than 1 year in $45 \%$ of patients, between 1 to 2 years in $32 \%$ and $>2$ years in $23 \%$. The biopsy score was A1F1 in most of the included patients $(54 \%)$. Most of these patients were married $(81 \%)$, nonsmokers $(54 \%)$, illiterate $(57 \%)$ and worked as unskilled workers (41\%). According to the social score $76 \%$ were of middle score. Most of the patients $(64 \%)$ did not record family history of hepatitis or psychiatric illness (89\%).

At 4 months follow up 7 patients did not continue their treatment as they had +ve PCR results with failure to respond to therapy. So the total number was 93 patients at that follow up. While at 6 months follow up another 5 patients discontinued their therapy as 2 of them developed severe leucopenia, 1 developed retinopathy and 2 patients stopped the IFN therapy because they preferred to receive direct acting anti-viral therapy (DAAs) instead. Thus the total number by the end of the study was 88 patients.

\section{Analysis of HD and HA scores}

According to the results of HD scores as shown in table 1 , all the patients had normal score at the start of the study. After 2 months of treatment, 69 patients $(69 \%)$ had abnormal score with 10 patients $(10 \%)$ had severe score and 5 patients $(5 \%)$ had very severe score. At
4 months follow up, 56 patients $(60.2 \%)$ had abnormal scores with 8 patients $(8.6 \%)$ had severe and 4 had very severe score $(4.3 \%)$. There were 3 new cases at this follow up. At the last follow up 53patients $(60.2 \%)$ had abnormal scores and 6 patients $(6.8 \%)$ had severe score and 2 patients $(2.3 \%)$ had very severe score. Four new cases appeared at this follow up. At each follow up, those with severe and very severe scores received antidepressant therapy in the form of selective serotonin reuptake inhibitors (SSRIs) as Sertraline tab with improvement of their condition. There was a high statistically significant difference between baseline and all follow up results $(p=0.000)$.

Assessment of HA scores as in table 2 showed that all patients at the start of the study had normal score with a mean $5.11 \pm$ 1.96. No cases at any follow up developed moderate or severe anxiety score. After 2 months there were 91 patients $(91 \%)$ had normal score and 9 patients $(9 \%)$ had mild score. After 4 months of treatment, 85 patients $(91.4 \%)$ had normal score and 8 $(8.6 \%)$ had mild score with three new cases. While by the end of the study there were 82 patients $(93.2 \%)$ had normal score and 6 patients $(6.9 \%)$ had mild score with one new case. All cases did not require pharmacological treatment as their score was mild. There was highly statistically significant difference between baseline and all follow up results $(p=0>000)$.

Table 3 illustrates the association between HD and HA scales and the socieodemographic characteristics of the included patients who developed depression and anxiety and we found that smoking was the only significant risk factors $(p=0.029)$ in patients with anxiety.

The correlation between HA and HD scores with the five factor model of personality during the whole study was studied and 
shown in tables 4 and 5 . There was a statistically significant correlation between HD and HA with neuroticism at 2, 4 and 6 months. Negative correlation was found between HA and HD scores with all other domains at the start of the study but with no statistically significant difference. However, negative correlation between $\mathrm{HA}$ with Conscientiousness was observed again after 2 months follow up with no significant difference.

Prevalence of IFN induced depression and anxiety shows wide variation among different studies. Saunders (2008) found that the frequency of depression in $\mathrm{HCV}$ patients was $16 \%$ to $58 \%$ (12). As regard anxiety, available data indicate that the prevalence is at least as high as that of depressive disorders and can range between $11 \%$ and $45 \%$ (13).

While Schaefer et al., (2012) found that about $30-70 \%$ of $\mathrm{HCV}$ infected patients develop different degrees of depression after treatment with IFN-alpha. Most of them suffer from mild or moderate symptoms, while severe major depression occurs in about 15\% (14). That agrees with our study which showed that $69 \%, 60.2 \%$ and $60.2 \%$ developed depression after 2 months, 4 months and 6 months, respectively of IFN therapy. While about $9 \%$, $8.6 \%$ and $6.9 \%$ developed anxiety at 2, 4 and 6 months follow up, respectively. Most of those who developed depression had mild to moderate symptoms with $19.7 \%$ developed severe and very severe depression. That did not result in discontinuation of the treatment particularly after receiving antidepressant therapy.

This difference in the frequency of depression and anxiety after treatment with IFN in this study with other studies could be due to difference in virus genotype, sample sizes, duration of follow up or psychiatric assessment tools. Thus, we recommend extension of the follow up period beyond 6 months as this could detect more cases. In a study by Sockalingam and Abbey (2009) most of HCV patients develop major depressive disorder within the first 12 weeks after treatment with IFN (15).

Table.1 Assessment of HD score for the included patients throughout the study

\begin{tabular}{|c|c|c|c|c|c|c|c|c|c|c|c|}
\hline & \multicolumn{2}{|c|}{$\begin{array}{l}\text { Baseline } \\
(n=100)\end{array}$} & \multicolumn{2}{|c|}{$\begin{array}{c}\text { After } 2 \mathrm{~m} \\
(\mathrm{n}=100)\end{array}$} & \multicolumn{2}{|c|}{$\begin{array}{c}\text { After } 4 \text { m } \\
(n=93)\end{array}$} & \multicolumn{2}{|c|}{$\begin{array}{c}\text { After } 6 \text { m } \\
(n=88)\end{array}$} & \multirow{2}{*}{$\begin{array}{c}\text { P- } \\
\text { value }^{1}\end{array}$} & \multirow[t]{2}{*}{ P-value $^{2}$} & \multirow{2}{*}{$\begin{array}{c}\text { P- } \\
\text { value }^{3}\end{array}$} \\
\hline & No. & $\%$ & No. & $\%$ & No. & $\%$ & No. & $\%$ & & & \\
\hline \multicolumn{9}{|l|}{ HD: } & \multirow{6}{*}{$0.000^{*}$} & \multirow{6}{*}{$0.000 *$} & \multirow{6}{*}{$0.000 *$} \\
\hline Normal & 100 & 100.0 & 31 & 31.0 & 37 & 39.8 & 35 & 39.7 & & & \\
\hline Mild & 0 & 0.0 & 44 & 44.0 & 32 & 34.5 & 35 & 39.7 & & & \\
\hline Moderate & 0 & 0.0 & 10 & 10.0 & 12 & 12.9 & 10 & 11.4 & & & \\
\hline Severe & 0 & 0.0 & 10 & 10.0 & 8 & 8.6 & 6 & 6.8 & & & \\
\hline Very Severe & 0 & 0.0 & 5 & 5.0 & 4 & 4.3 & 2 & 2.3 & & & \\
\hline Mean \pm SD & \multicolumn{2}{|c|}{$6.65 \pm 2.25$} & \multicolumn{2}{|c|}{$10.88 \pm 6.59$} & \multicolumn{2}{|c|}{$9.94 \pm 6.94$} & \multicolumn{2}{|c|}{$9.27 \pm 5.90$} & \multirow{3}{*}{$0.000 *$} & \multirow{3}{*}{$0.000 *$} & \multirow{3}{*}{$0.000 *$} \\
\hline Median & \multicolumn{2}{|c|}{8.0} & \multicolumn{2}{|c|}{10.0} & \multicolumn{2}{|c|}{10.0} & \multicolumn{2}{|c|}{9.0} & & & \\
\hline Range & \multicolumn{2}{|c|}{$0-8$} & \multicolumn{2}{|c|}{$0-29$} & \multicolumn{2}{|c|}{$0-28$} & \multicolumn{2}{|c|}{$0-25$} & & & \\
\hline
\end{tabular}

Abbreviations: p- value ${ }^{1}$ difference between baseline and 2 months follow up, $\mathrm{p}$ - value ${ }^{2}$ : difference between baseline and 4 months follow up, p- value ${ }^{3}$ : difference between baseline and 6 months follow up 
Table.2 Assessment of HA scores in the studied patients throughout the study

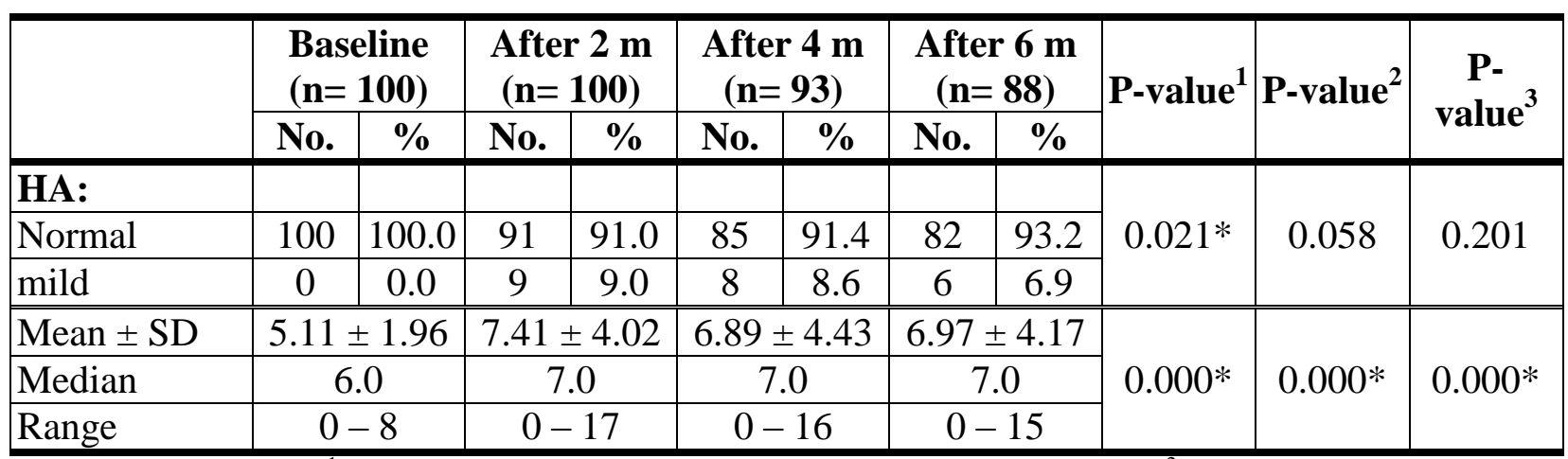

Abbreviations: $p$ - value ${ }^{1}$ : difference between baseline and 2 months follow up, $p$ - value ${ }^{2}$ : difference between baseline and 4 months follow up, $p$ - value ${ }^{3}$ : difference between baseline and 6 months follow up

Table.3 Association between HA and HD with the socieodemographics of the included patients

\begin{tabular}{|l|c|c|}
\hline & HA & HD \\
\cline { 2 - 3 } & Mean \pm SD & Mean \pm SD \\
\hline Age: & & \\
\hline$<30$ years & $5.62 \pm 1.60$ & $7.29 \pm 1.19$ \\
\hline $30-<40$ years & $4.58 \pm 2.22$ & $5.67 \pm 2.55$ \\
\hline $40-<50$ years & $5.23 \pm 1.78$ & $7.00 \pm 2.01$ \\
\hline$\geq 50$ years & $4.94 \pm 2.32$ & $6.44 \pm 2.94$ \\
\hline $\boldsymbol{P}$-value & 0.473 & 0.065 \\
\hline Sex of patients: & & \\
\hline Male & $5.11 \pm 2.04$ & $6.60 \pm 2.35$ \\
\hline Female & $5.08 \pm 1.38$ & $7.00 \pm 1.41$ \\
\hline $\boldsymbol{P}$-value & 0.509 & 0.982 \\
\hline Occupational: & & \\
\hline Employee & $5.75 \pm 0.50$ & $7.75 \pm 0.50$ \\
\hline Farmer & $5.11 \pm 2.33$ & $6.30 \pm 2.69$ \\
\hline Housewife & $5.09 \pm 1.22$ & $7.09 \pm 1.38$ \\
\hline Not work & $5.86 \pm 2.61$ & $6.71 \pm 2.98$ \\
\hline Skilled worker & $4.80 \pm 1.87$ & $6.60 \pm 2.46$ \\
\hline Unskilled worker & $5.00 \pm 1.90$ & $6.66 \pm 2.08$ \\
\hline $\boldsymbol{P}$-value & 0.407 & 0.893 \\
\hline Education: & & \\
\hline Illiterate & $5.11 \pm 1.88$ & $6.67 \pm 2.19$ \\
\hline Primary & $4.94 \pm 1.75$ & $6.53 \pm 1.94$ \\
\hline Secondary & $5.29 \pm 2.20$ & $6.83 \pm 2.43$ \\
\hline College & $4.80 \pm 2.77$ & $6.00 \pm 3.39$ \\
\hline P-value & 0.771 & 0.553 \\
\hline Marital state: & & $6.94 \pm 1.73$ \\
\hline Single & $5.22 \pm 1.83$ & $6.57 \pm 2.36$ \\
\hline Married & $5.07 \pm 2.00$ & \\
\hline
\end{tabular}




\begin{tabular}{|l|c|c|}
\hline Divorced & 6.00 & 8.00 \\
\hline $\boldsymbol{P}$-value & 0.948 & 0.709 \\
\hline Smoking: & & \\
\hline Non smoking & $4.85 \pm 2.05$ & $6.43 \pm 2.37$ \\
\hline Cigarette smoker & $4.96 \pm 1.73$ & $6.71 \pm 2.12$ \\
\hline Ex-smoker & $5.45 \pm 2.25$ & $6.73 \pm 2.53$ \\
\hline Gauza smoker & $6.36 \pm 1.21$ & $7.55 \pm 1.51$ \\
\hline $\boldsymbol{P}$-value & $\mathbf{0 . 0 2 9} *$ & 0.165 \\
\hline Social score: & & \\
\hline Low & $4.36 \pm 1.91$ & $5.73 \pm 2.49$ \\
\hline Middle & $5.24 \pm 1.91$ & $6.76 \pm 2.14$ \\
\hline High & $5.00 \pm 2.27$ & $6.77 \pm 2.62$ \\
\hline $\boldsymbol{P}$-value & 0.241 & 0.183 \\
\hline $\begin{array}{l}\text { Duration of hepatitis } \\
\text { in month: }\end{array}$ & & \\
\hline$<1$ year & $5.36 \pm 1.61$ & $7.09 \pm 1.68$ \\
\hline 1 - <2 years & $5.41 \pm 1.52$ & $7.13 \pm 1.36$ \\
\hline$\geq 2$ years & $4.22 \pm 2.78$ & $5.13 \pm 3.36$ \\
\hline $\boldsymbol{P}$-value & 0.425 & 0.099 \\
\hline
\end{tabular}

There was a highly statistically significant correlation between HA and HD scales $(p=0.000)$.

Table.4 Correlation between HD and the five factor model of personality

\begin{tabular}{|l|l|c|c|c|c|c|}
\hline \multicolumn{1}{|c|}{ HD } & & Neuroticism & Extraversion & Openness to experience & Agreeableness & Conscientiousness \\
\hline \multirow{2}{*}{$\begin{array}{l}\text { At } \\
\text { baseline }\end{array}$} & r-value & 0.62 & -0.38 & -0.039 & -0.048 & -0.018 \\
\cline { 2 - 7 } & P-value & 0.540 & 0.704 & 0.700 & 0.638 & 0.857 \\
\hline \hline \multirow{2}{*}{$\begin{array}{l}\text { After } \\
\text { 2 months }\end{array}$} & r-value & $\mathbf{0 . 3 0 6}$ & 0.156 & 0.074 & 0.048 & 0.057 \\
\cline { 2 - 7 } & P-value & $\mathbf{0 . 0 0 2 *}$ & 0.122 & 0.463 & 0.634 & 0.576 \\
\hline \hline $\begin{array}{l}\text { After } \\
\text { 4 months }\end{array}$ & r-value & $\mathbf{0 . 2 8 4}$ & 0.076 & 0.009 & 0.057 & 0.034 \\
\cline { 2 - 7 } $\begin{array}{l}\text { After } \\
\text { 6 months }\end{array}$ & P-value & $\mathbf{0 . 0 0 6 *}$ & 0.467 & 0.929 & 0.038 & 0.747 \\
\cline { 2 - 7 } & P-value & $\mathbf{0 . 2 8 7}$ & 0.031 & 0.003 & 0.728 & 0.061 \\
\hline
\end{tabular}

Table.5 Correlation between HA and the five factor model of personality

\begin{tabular}{|l|l|c|c|c|c|c|}
\hline \multicolumn{1}{|c|}{ HA } & & Neuroticism & Extraversion & Openness to experience & Agreeableness & Conscientiousness \\
\hline \multirow{2}{*}{$\begin{array}{l}\text { At } \\
\text { baseline }\end{array}$} & r-value & 0.131 & -0.065 & -0.040 & -0.096 & -0.055 \\
\cline { 2 - 7 } & P-value & 0.193 & 0.518 & 0.696 & 0.342 & 0.590 \\
\hline \hline \multirow{2}{*}{$\begin{array}{l}\text { After } \\
\text { months }\end{array}$} & r-value & $\mathbf{0 . 3 2 0}$ & 0.114 & 0.068 & 0.019 & -0.012 \\
\cline { 2 - 7 } $\begin{array}{l}\text { After } \\
\text { 4 months }\end{array}$ & r-value & $\mathbf{0 . 0 0 1 *}$ & 0.259 & 0.503 & 0.847 & 0.902 \\
\cline { 2 - 7 } & P-value & $\mathbf{0 . 2 5 9}$ & 0.121 & 0.078 & 0.097 & 0.076 \\
\hline $\begin{array}{l}\text { After } \\
\text { 6 months }\end{array}$ & r-value & $\mathbf{0 . 0 1 2 *}$ & 0.249 & 0.457 & 0.107 & 0.468 \\
\cline { 2 - 7 } & P-value & $\mathbf{0 . 0 1 3 *}$ & 0.019 & 0.014 & 0.319 & 0.111 \\
\hline
\end{tabular}


A recent study in Egypt showed that 37.9\% and $46.6 \%$ of treated $\mathrm{HCV}$ patients developed major depressive disorder (MDD) and generalized anxiety disorder (GAD), respectively, after 12 weeks of treatment by IFN and ribavirin (16).

Our results showed that most of patients developed depression and anxiety after 2 months of starting the treatment $(69 \%)$ and $(9 \%)$, respectively.

This can be due to suffering of patients from stress while waiting the result of PCR that appears at week 12 and 24 of treatment.

Significant relationships were found between increases in serumIL-6 or IL-8 induced by treatment using IFN-a in chronic $\mathrm{HCV}$ patients and the scores of depression and anxiety after 2 to 4 weeks of starting IFN-a therapy (17).

Increase symptoms of depression during IFN therapy has been explained by depletion of serotonin, decreases in tryptophan, and increases in tryptophan catabolism (18).

Regarding socioeconomic factors, in a study of $92 \mathrm{HCV}$ patients undergoing IFN-a therapy, the authors examined a number of socioeconomic variables and medical characteristics, and the only risk factor for depression was advanced age(19).

According to a meta-analysis of 26 studies, high baseline serum IL- 6 level, female gender, history of psychiatric disorder, subthreshold depressive symptoms, and low educational level predict the development of depression during antiviral treatment (20).

Another study evaluated risk factors of depression in chronic hepatitis $\mathrm{C}$ patients showed that female gender, baseline anxiety symptoms, increased in dose of the interferon and longer time duration of the therapy as the most important in the development of depression during the treatment (14).

While by analysis of the socieodemographic factors in this study we found that smoking was the only significant risk factors for development of anxiety $(\mathrm{p}=0.029)$.

In this study, analysis of the risk factors showed that there was a significant correlation between depression and anxiety $(p=0.000)$ throughout the whole study period.

Biopsy and PCR results did not show a significant difference which suggest that the development of depression and anxiety in our studied patients is not caused by the hepatitis $\mathrm{C}$ virus itself but related to the effect of the treatment as all the included patients had negative PCR results by the end of the study. However, Pattullo et al., (2011) concluded that the effect of chronic HCV infection may be irreversible even after viral clearance from the serum (21). In the current study neuroticism was also a risk factor for development of both depression and anxiety during the whole study period.

Psychiatric assessment of patients in our study revealed that depression and anxiety developed due to several patients concerns. Patients usually develop side effects of IFN that decrease their health related quality of life (HQOL) such as fatigue and pain which could cause frequent absence of their work. Development of other side effects like erectile dysfunction in males and leucopenia with frequent episodes of infections is another risk factor. At the same time, the need for many and frequent investigations during treatment lead to expending a lot of time and money on each follow up.

Concerns regarding the long duration of treatment with fear of failure of response 
could also contribute to development of depression and anxiety in our patients. Many patients also had concerns regarding rumors about presence of new medical treatment such as DAAs and questions about their efficacy and safety in comparison to IFN.

IFN - induced depression and anxiety in chronic HCV patients are common. Most of these cases occur early after initiation of the therapy. These are considered side effects of the drug and not direct effect of the virus. Hence, these side effects require careful monitoring during treatment using IFN- a to prevent discontinuation of the treatment and to initiate treatment by antidepressants as early as possible. Thus, psychiatric assessment of patients eligible to IFN is necessary before initiation of treatment and thereafter. Further studies on these side effects for longer duration and in cancer patients receiving IFN therapy would be recommended.

\section{References}

1.Mohd Hanafiah K, Groeger J, Flaxman AD, Wiersma ST. Global epidemiology of hepatitis $\mathrm{C}$ virus infection: new estimates of age specific antibody to HCV seroprevalence. Hepatology. 2013;57:1333-42.

2.Mohamoud Y, Mumtaz G and Abu-Raddad L. The epidemiology of hepatitis C virus in Egypt: a systematic review. Int J Infect Dis 2012; 16: 2-157.

3.Piper, J.M., Wen, T.T., Xenakis, E.M., 2001. Interferon therapy in primary care. Prim. Care Update Ob Gyns 8, $163-169$.

4.Dieperink, E., Willenbring, M., Ho, S., 2000. Neuropsychiatric symptoms associated with hepatitis $\mathrm{C}$ and interferon alpha: areview. Am. J. Psychiatry 157, 867-876.

5.Fried, M.W., Shiffman, M.L., Reddy, K.R.,
Smith, C., Marinos, G., Goncales Jr., F.L., Haussinger, D., Diago, M., Carosi, G., Dhumeaux, D., Craxi, A., Lin, A., Hoffman, J., Yu, J. 2002. Peginterferonalfa-2a plus ribavirin for chronic hepatitis $\mathrm{C}$ virus infection. N.Engl. J. Med. 347, 975- 982.

6.Malek-Ahmadi, P., 2001. Mood disorders associated with interferon treatment: theoretical and practical considerations. Ann. Pharmacother.35, 489- 495.

7.Morasco BJ, Rifai MA, Loftis JM, et al. A randomized trial of paroxetine to prevent interferon-alpha-induced depression in patients with hepatitis $\mathrm{C}$. J Affect Disord 2007; 103: 83-90.

8.Catherine CC, Gabriel GM and Wise TN. Managing the neuropsychiatric side effects of interferon-based therapy for hepatitis C. Cleve Clin J Med 2004; 71: 27-32.

9.First MB, Spitzer RL, Gibbon M. \& Williams JB (1996). Structured Clinical Interview for the DSM-IV Axis I Disorders.

10.Timothy J. Trull and Thomas A. Widiger, (2013) Dimensional models of personality:the five-factor model and the DSM-5. Dialogues in Clinical Neuroscience; (15)135-146.

11.Abdel-Tawab, M.A. (1998): Socioeconomic scale for family, revised edition. M.D. thesis in educational basics, Faculty of Education, Assiut University, 3: 32-55.

12.Saunders JC. Neuropsychiatric symptoms of hepatitis C. Issues Ment Health Nurs 2008; 29: 209-220.

13.Bagheri H, Fouladi A, Barange K, et al. Follow-up of adverse drug reactions from peg Interferon alpha2b-ribavirin therapy. Pharmacotherapy 2004; 24: 1546-1553.

14.Schaefer M, Capuron L, Friebe A, DiezQuevedo C, Robaeys G, Neri S, Foster GR, Kautz A, Forton D, Pariante CM: 
Hepatitis C infection, antiviral treatment and mental health: a European expert consensus statement. J Hepatol 2012, 57:1379-1390.

15.Sockalingam S and Abbey SE. Managing depression during hepatitis $\mathrm{C}$ treatment. Can J Psychiatry 2009; 54: 614-625.

16.Bassiony MM, Yousef A, Youssef U, Salah El-Deen GM, Abdelghani M,AlGohari H, Fouad E, and ElShafaeyMM : Major depressive disorder and generalized anxiety disorder and response to treatment in hepatitis Cpatients in Egypt. The International Journal of Psychiatry in Medicine 2015: 1-16

17.Bonaccorso, S., Puzella, A., Marino, V., Pasquini, M., Biondi, M., Artini, M., Almerighi, C., Levrero, M., Egyed, B., Bosmans, E., Meltzer, H.Y., Maes, M., 2001. Immunotherapy with interferon alphain patients affected by chronic hepatitis $\mathrm{C}$ induces an intercorrelated stimulation of the cytokine network and an increase in depressive and anxiety symptoms. Psychiatry Res.105, 45-55.

18.Loftis JM and Hauser P(2004): The phenomenology and treatment of interferon-induced depression. Journal of Affective Disorders 82 : 175-190

19.Horikawa N, Yamazaki T, Izumi, N \&Uchihara, M 2003. Incidence and clinical course of major depression in patients with chronic hepatitis type $\mathrm{C}$ undergoing interferon-alpha therapy: a prospective study. Gen Hosp Psychiatry 25: 34-38.

20.Udina M, Castellvi P, Moreno-Espana J, et al. Interferon-induced depression in chronic hepatitis $\mathrm{C}$ : a systematic review and meta-analysis. J Clin Psychiatry 2012;73: 1128-1138.

21.Pattullo V, McAndrews M, Damyanovich $\mathrm{A}$, et al. Influence of hepatitis $\mathrm{C}$ virus on neurocognitive function in patients free from other risk factors: validation from therapeutic outcomes. Liver Int 2011; 31: 1028-1038.

\section{How to cite this article:}

Sahar M. Hassany, Alaa M. Darwish, Hossam Khalifa, Gellan K. Ahmed, Haidi Karam Alla Ramadan and Ehab F. Moustafa. 2017. Prevalence and Risk Factors of Depression and Anxietyin Hepatitis C Patients Receiving Pegylated Interferon Alpha (IFN-a). Int.J.Curr.Microbiol.App.Sci. 6(10): 484-493. doi: https://doi.org/10.20546/ijcmas.2017.610.059 